\title{
DESENVOLVIMENTO COMO IDEIA UNÍVOCA: ALGUNS APONTAMENTOS PARA A REFLEXÃO*1
}

\section{DEVELOPMENT AS A UNIVOCAL IDEA: SOME NOTES FOR REFLECTION}

\author{
Diana Manrique García ${ }^{2}$ \& Tatiana Engel Gerhardt ${ }^{3}$ \\ alunadiana@gmail.com - tatiana.gerhardt@ufrgs.br \\ Universidade Federal do Rio Grande do Sul \\ Porto Alegre, Brasil
}

\section{RESUMO}

O artigo surge como peça de uma proposta de pesquisa doutoral em andamento, ainda em construção e desconstrução, que parte de questionar o que estamos entendendo como desenvolvimento. O lugar de posicionamento, de enunciação precisa ser desestabilizado e abrir fissuras que possibilitem refletir e trazer a nossas discussões a complexidade, mutabilidade e incomensurabilidade dos mundos com os que se interage. Os olhares do desenvolvimento na academia seguem presos nas lógicas economicistas colonizadoras da modernidade e deixam de lado outras práticas e saberes como os produzidos na mesma America latina -o caso de bom viver entre outros conceitos- que podem aportar desafios e possibilidades epistêmicas para trabalhar uma década de realidades pigmentadas de catástrofes. Frente a isto, a academia, as ciências sociais e o trabalho social devem evitar as categorias reducionistas do mundo e possibilitar novos métodos e escritas que contribuam para dar conta da multiplicidade da vida. Fato que se pretende ilustrar com um estudo de caso da Amazônia boliviana.

Palavras-chaves: Desenvolvimento, academia, decolonialidade, ontologias.

\begin{abstract}
The article appears as part of a doctoral research proposal in progress, still under construction and deconstruction, which starts from questioning what we are understanding as development. The place of positioning, of enunciation needs to be destabilized and open cracks that make it possible to reflect and bring to our discussions the complexity, mutability and immeasurability of the worlds with which we interact. The views of development in academia remain trapped in the economicist logics that colonized modernity and set aside other practices and knowledge such as those produced in the same Latin America - the case of good living among other concepts- that can bring challenges and epistemic possibilities to work a decade of pigmented realities of catastrophes. Faced with this, academia, the social sciences and social work must avoid the reductionist categories of the world and enable new methods and writings that contribute to account for the multiplicity of life. This fact is intended to be illustrated with a case study of the Bolivian Amazon.
\end{abstract}

\footnotetext{
* Artículo recibido el 31 de enero de 2018; aceptado el 30 de marzo de 2018.

${ }^{1}$ Este artículo correpsonde al proyecto de investigación doctoral en que participan las autoras.

2 Doctoranda en Programa de Pos graduación en Desarrollo Rural -PGDR-, Universidad Federal Río Grande del Sur -UFRGS-.

${ }^{3}$ Académica Programa de Pos graduación en Desarrollo Rural -UFRGS-, Programa de Pos graduación en Salud Colectiva -UFRGS-. Coordinadora de la comisión de Ciencias Sociales y Humanas en salud de la Asociación Brasilera de Salud Colectiva -ABRASCO-
} 
Key words: Development, academy, decoloniality, ontologies.

\section{Introdução}

Os estudos do desenvolvimento rural transitam por muitas complexidades, não só acadêmicas, mas talvez pensar o desenvolvimento já é uma complexidade que começa no mesmo conceito. O que é desenvolvimento e por que estudar-falar dele? É aqui que se inicia o recorrido com a intenção não de obter respostas desde um postulado de verdade, mas como possibilidade de lograr uma aproximação e problematização destes campos de estudos e como nestes pode-se aportar, ampliar e enriquecer os debates das ruralidades. Embora, não se pretende trazer para discussão a diversidade de autores/as e atores que têm pesquisado e escrito sobre o tema, mas alguns trabalhados no decorrer do processo de formação da pós-graduação em desenvolvimento rural que podem jogar algumas pistas.

A intenção aqui é trazer elementos que apontem na reflexão da ideia do desenvolvimento como um eixo histórico ligado restritamente ao campo econômico e político, deixando fora outros possíveis horizontes que podem contribuir no entender a complexidade da vida, dos mundos com os que se interage e dos problemas sociais contemporâneos que demandam a atenção não só da academia, mas também das políticas públicas e sociais.

O trabalho está organizado da seguinte forma. Primeiramente se traz um breve recorrido crítico na conceituação do desenvolvimento conforme algumas referências centrais na matéria, principalmente na literatura sobre o desenvolvimento rural, na sequencia se apresentam algumas leituras alternativas ou críticas ao desenvolvimento, onde não seja o econômico ou político as únicas possíveis formas para pensar nele, para finalmente deixar abertas algumas possibilidades na criação do conhecimento nas ciências sociais e especificamente no campo do trabalho social a partir da experiência no mundo rural na Amazônia boliviana.

\section{Desfazendo certezas}

Alguns estudiosos do conceito do desenvolvimento têm se dedicado a sua discussão desde diferentes ângulos, mas ressaltam os estudos onde o desenvolvimento centra-se no olhar desde uma perspectiva econômica-política como eixos principais. Como expõe Escobar (2005, 2008, 2014) no último meio século o conceito de desenvolvimento nas ciências sociais identifica três momentos associados com três linhas teóricas: modernização, dependência e crítica do desenvolvimento como os discursos culturais; os dois primeiros correspondentes a modelos estruturais, com domínios nas décadas de 50,60 e 70, e se bem eles representam posições ideologicamente opostas, concordam com o fato de que correspondem a ideias lineares que concebem o desenvolvimento e as mudanças sociais como algo que emerge dos centros de poder, seja Estado ou organização internacional e suas diversas formas de intervenção propostas, seguindo um caminho estabelecido do desenvolvimento e suas diversas fases, ou a sucessão dos modos dominantes de produção (Long e Ploeg, 2011).

A última dessas tendências é característica da fase 80 e 90, localizada dentro das críticas do pós-estruturalismo, essa, em vez de sugerir outra proposta de desenvolvimento, concentra-se no questionamento dessa construção e da relação de desenvolvimento - subdesenvolvimento, convidando a questionar a determinação externa; como exemplo disto pode-se trazer o exposto por Fonseca, quem se referindo ao desenvolvimentismo, expõe que diferente do liberalismo, este brotou como consciência do atraso e como busca de uma estratégia nacional para superá- 
lo. Fenômeno, portanto, peculiar da própria América Latina e de outros com problemática semelhante (Ásia e África) (Fonseca, 2015).

Assim, pode-se postular que as duas primeiras linhas são as que têm um legado maior no mundo dos estudos de desenvolvimento, de uma parte podem responder a que fazem parte da invenção do conceito neste quadro colonialista posterior à segunda guerra mundial que destaca a pobreza como eixo principal e fator próprio de países subdesenvolvidos, que de acordo com o Banco Mundial precisa estratégias de intervenção planejadas. Nessa ideia, para Fonseca (2015) o desenvolvimentismo brotou como consciência do atraso e como parte de uma estratégia nacional para superá-lo, da mão da comissão econômica para América latina e o Caribe -CEPALC-. A invenção do terceiro mundo, a criação da ideia de subdesenvolvimento e seus diversos jeitos de intervenção, trazem no centro do cenário a pobreza e o discurso de seu combate e necessidade de erradicação, junto aquilo a possibilidade do manejo racional dela, é assim que frente à declaração do banco Mundial em 1948, onde os pobres passam a ser dois terços da população mundial, o crescimento econômico apresenta-se como a solução (Escobar, 2007).

Emerge o problema da pobreza na escala global e como limitante dos países desenvolvidos, precisando destes o controle e vigilância possível, ou que no manejo racional se traduz no planejamento e na formação de profissionais especializados que fazem parte das esferas do Estado ou seus assessoramentos. Se bem, não pode falar-se de maneira homogênea no caso de América latina, enquanto não é um processo uniforme, é possível observar como depois do consenso de Washington se dá uma fraqueza fiscal, financeira e perda de capacidade de arbitramento das políticas dos estados nacionais induzindo à subordinação das políticas econômicas estadunidenses e aumentando o poder dos grupos ligados ao capital internacional. (Cano, 1999).

Segundo Leite (2006) a caracterização da noção de padrão de desenvolvimento tem uma íntima relação com o perfil de intervenção estatal, enquanto este se responsabilizou pela promoção do crescimento e administração do ciclo econômico, pela forma de distribuição de renda e da riqueza em geral e pelo controle dos interesses multinacionais. O autor expõe como no caso do Brasil, o conceito de desenvolvimento vem acoplado à dimensão econômica e as suas possibilidades de interpretar os processos pertencentes ao meio rural. Ele se centra no estudo da agricultura e desenvolvimento no caso Brasileiro.

O aprofundamento da relação entre economia e política, ou entre Estado e acumulação de capital no contexto "intervencionista", onde o Estado se fixa tanto na órbita política como econômica, deriva para Faletto (Faletto apud Leite 1989), do caráter dependente das sociedades latino-americanas, nas quais o problema da eficiência da ação econômica estatal não decorre única e exclusivamente da capacidade tecno-burocrática, mas também das intrincadas relações de poder. Assim no mesmo estudo, Leite (2006), se entende o Estado desenvolvimentista como aqueles Estados que extraem excedentes, mas também fornecem bens coletivos. Fomentam perspectivas empresariais de longo prazo entre elites privadas mediante o aumento de incentivos ao engajamento em investimentos transformadores e a redução dos riscos envolvidos em tais investimentos.

É difícil precisar de que desenvolvimento fala-se, mas é claro que nestas reflexões e analises há uma lógica estrutural onde aparece o estado ou as intervenções internacionais como forças do conceito, embora Fonseca (2015) já sugira a ambiguidade do conceito quanto ao espectro denotativo por ele coberto. Entende-se que o conceito corresponde a um fenômeno que de uma parte depende da realidade histórica das políticas econômicas, quanto da ideia no discurso político, para ele se requere do real e ideal na construção do conceito. Seguindo este postulado, 
o material e o ideal depara uma sorte de ponto de encontro na definição. $O$ autor também estuda outros trabalhos - Echevarría, Evans, Já Wade, Já Chang, Bresser Pereira- os quais centram-se na definição do que denominam "Estados desenvolvimentistas" - e na política econômica a ele associada -, nesta aproximação conceitual do desenvolvimentismo olha-se menos como ideologia, mas sem, todavia, deixarem de admitir que uma ideologia também se faz presente para nortear e justificar as medidas tomadas pelos governantes (Fonseca,2015).

Segundo este mesmo autor, nenhum conceito é definitivo e, como objeto social, está sempre em movimento, assim como o objeto a ser conceituado. Mas é importante olhar que ele considera que deles não se pode prescindir: sem categorias teóricas não é possível o trabalho científico. A necessidade de estabelecer parâmetros mínimos aporta em evitar polêmicas desnecessárias, além de auxiliar no estudo do próprio objeto, pois a construção do conceito exige lastro empírico antes do salto para a abstração. Postura que já indica um posicionamento na concepção de ciência do autor.

A ideia que o conceito, em uma dada formação capitalista, pode ser definido como o "conjunto de relações entre os agentes econômicos e sociais que garante, ao longo de um período de tempo, a manutenção dos processos de acumulação de capital e de preservação do poder político" (Leite, 2006), faz suspeitar que com a emergência do capitalismo, a realidade, o real, reduz-se àquilo que pode visualizar-se só dentro das coordenadas racionais do econômico, desta trama onde a estrutura social e histórica fica presa da ordem econômica (Composto e Navarro, 2014).

No concreto destes processos, nas realidades de América latina, o estado nacional desenvolvimentista como um padrão de desenvolvimento adotado na década de 40 (Leite, 2006) nos fins da década dos 80 foi perdendo seu poder, os investimentos se fazem cada vez menores e a dívida e os juros aumentam, o que possibilita na década dos 90 , abrir a porta para chamada modernidade. Múltiplas reformas aparecem na cena de América latina onde a internacionalização dos capitais, a liberalização dos mercados e a privatização dos ativos e serviços públicos fazem parte do receituário. Produtividade e competitividade são os eixos centrais de suas linguagens.

É assim neste cenário que múltiplos autores decorrem tentando fazer uma aproximação às lógicas conceituais mais centradas na lógica do capitalismo(,) onde se percebe uma ideia do conceito próxima a crescimento econômico e de outra traz uma concepção linear associada ao "progresso" em relação ao "atraso". Pode-se identificar se uma heterogeneidade de análises, mas o ponto de convergência que se encontra, pode ser no que para Leite pode chamar-se esgotamento do padrão nacional desenvolvimentista (2006) ou a sustentabilidade do modelo como algo impossível (Cano, 1999).

Fonseca por sua parte questiona por que determinados termos teóricos persistem, mesmo quando certas condições históricas nas quais apareceram se alteram? Seguindo ele, no caso de desenvolvimentismo, as respostas são simples: as condições históricas ou os "problemas" que deram ensejo ao seu aparecimento - manifestos sob diferentes formas e com termos diferentes- não foram superados (Fonseca 2010, 2013). Agora bem, não é preciso levantar algumas questões relativas ao que eles exibem como esgotamento, insustentabilidade ou persistência? A pesar de que eles mesmos logram dar conta de análises e possibilidades, não conseguem falar fora desse mesmo quadro de análises onde necessariamente nos remete a relação economia e política, entre acumulação de capital e estado, onde sempre passa por aumento da produção e da produtividade, modernização e política econômica. 
Como se menciono no começo do texto, nas últimas duas décadas a noção do desenvolvimento esteve atravessada por mudanças que se concentram no questionamento dessa construção e da relação de desenvolvimento - subdesenvolvimento, convidando a questionar a determinação externa e estando muito mais influídas pela participação dos diferentes grupos e os movimentos sociais. Ainda assim, Escobar (2008) argumenta que esta reorientação política se conforma de inclinações opostas, uma das quais caracteriza esta transformação enquanto cooptação da linguagem dos movimentos sociais pelo sistema estatal. A segunda acha um nível de influência mais incisivo dos movimentos sociais sobre as ações estatais.

Por sua parte, Walsh sinaliza que estas perspectivas dirigidas à participação e ao incremento da inclusão dos grupos marginados anteriormente só faz parte duma continuidade do projeto neoliberal onde se reproduz a imposição moderna e colonial própria da concepção do desenvolvimento. Onde apresenta-se um fim único ao qual se quer chegar ou alcançar, que para a autora se traduz em iniciativas que procuram garantir a conformidade e fazer todos os grupos funcionais ao capitalismo, enquanto submete a diversidade ao único eixo de produção e valoração (Walsh, 2010).

\section{Horizontes possíveis}

Nessa lógica a conceituação do desenvolvimento não pode tomar distância do eixo econômico, entendido primordialmente como uma política econômica efetivamente praticada de formas diferentes, porém próximas pelos governos em determinado tempo e lugar. É preciso olhar que para fazer uma aproximação crítica ao desenvolvimento e suas nuances, se faz necessário compreender que, como expõe Dávalos, o conceito de desenvolvimento e crescimento econômico superam seu próprio conteúdo, quando se fala deles não se pode reduzir a um conjunto de técnicas, políticas, estratégias, discursos e práxis que tem em sua razão na economia e seus discursos. É preciso dar conta que estes conceitos têm um excedente simbólico além da economia e política e por mais crítico que se apresenta as aproximações a eles, não pode reduzir-se o simbólico a lógica analítica e estudo racional que os caracteriza (Dávalos apud Composto e Navarro, 2014).

A necessidade de ir além destes postulados economicistas, se sustenta de uma parte na incapacidade e esgotamento daqueles para dar respostas às complexas realidades atuais e de outra, na possibilidade de problematizar estes discursos e sua gênese eurocêntrica, traduzida em práticas colonizadoras e que de acordo com a terceira linha exposta por Escobar, sugerem denunciar e destruir as ontologias que fazem possível a dominação colonial (Castro, 2007).

Por que fazer este chamado de ir além? Por que expor a necessidade de olhar outras perspectivas? Citando como exemplo a Favareto, quando fala no caso do Brasil de resultados positivos em matéria de desenvolvimento, expõe que não há dúvidas de que a década 20002010 foi uma década vitoriosa em vários aspectos, - houve uma acentuada redução da pobreza e uma inédita redução da desigualdade, o país experimentou um crescimento econômico continuado, redução do ritmo do desmatamento, maior democratização (Favareto, 2010). Sem problematizar a ideia de desenvolvimento com que ele trabalha, o questionamento é a que custos em matéria ambiental ou social - e outras tantas coisas que se podem polemizar-, que tem significado esses alcances positivos nos indicadores econômicos criados, mesmo, desde as necessidades homogeneizantes e hegemônicas pelas que se mede o desenvolvimento?

Por outro lado e ampliando a discussão podemos trazer problematizações como as expostas por Saskia Sassem (Batisto, 2015) quando fala da emergência de novas e perigosas dinâmicas da economia capitalista como as de expulsão, fato que gera a necessidade de falar hoje, não só de desigualdade extrema, maior pobreza, aumento das populações penais, crescimento da 
destruição ambiental, mas também dar conta da transformação sistêmica mais profunda onde acontecem processos com resultados extremos aos que se chama sob o nome de expulsão, do que acontece nas margens sistêmicas, mas que dá conta, por exemplo, não só de degradação, também de terra morta e água morta, de vida que deixou de viver. ${ }^{4}$

Seguindo a mesma autora, precisa-se de novos critérios para pensar o crescimento econômico que responda a uma nova lógica distributiva que envolva as pessoas e responda a realidades locais e territoriais. Não é deixar de conhecer e estudar aquilo que se busca mudar é só superar o enclave colonial sob o qual não só estudamos as realidades, mas também terminamos fazendo uma sorte de premonição determinista unívoca que esquece as possibilidades de outros mundos que existem nos paralelos, que se justapõem, cruzam ou entrelaçam. Isto não é só um chamado acadêmico, não é um romantismo pré-moderno como gostam de nominar muitos cegos na fé da razão, é uma tentativa de refletir quando a vida mesma do planeta está em risco e precisa-se de alternativas que estão fora da lógica da barbárie gerada pela acumulação capitalista.

As propostas atrativas de modernidade, racionalidade que se propõem ordenar o mundo de acordo com os parâmetros ocidentais homogêneos e universalizastes atualmente é questionada por diversos autores, destacam-se neste trabalho os apontamentos de Escobar e outros autores- Mignolo, Blasser Pereira, Quijano, Rivera Cusicanqui, Boaventura de Sousa entre outros- identificados nos caminhos dos estudos críticos decoloniais. O convite busca abrir outras possibilidades de compreender a realidade social a partir primeiramente da desconstrução daqueles conceitos que são a ferramenta principal nos discursos e que pretendem, baixo uma lógica totalizante, homogeneizar aqueles mundos que estão fora das produções de conhecimento dominante e que dá conta de alternativas e resistem à definição e redução do moderno ou existem além dela.

Embora, a ideia de trazer para a discussão essas outras realidades não pretende constituir-se como discursos de verdade, pois ficaria na mesma lógica reducionista e hierárquica da dominação colonial, quiçá só pretende de uma parte questionar como no plano da academia, se seguimos reproduzindo os discursos dominantes como discursos de verdade (como práticas únicas) podemos ficar atrapalhados circulando sobre o mesmo sem contribuições significativas que problematizem as realidades, de outra parte buscar faixas e luzes que possam visualizar realidades silenciadas, que só falam de outras formas que se existe e resiste nos mundos além do predomínio econômico.

Assiste-se a uma crise da ideia de "progresso" e "desenvolvimento" porque os dois sugerem um problema de excesso e risco, mas não estão percebidos assim (Blaser, 2010), e são pensados de maneira unilinear e traduzem na forma de políticas extrativistas transgressoras da natureza. Temos um esgotamento da ontologia dualista que sustenta o modelo colonial presente no estado nação, junto àquilo é inevitável fazer uma crítica e questionamento radical das ideias de totalitarismo economicista encoberto em conceitos como desenvolvimento, crescimento, progresso, extrativismo, reformas de mercado, consumo material, entre outras.

Assim se faz uma necessidade nutrir olhares críticos sobre o desenvolvimento, além do mesmo conceito, marco onde emergem como possibilidade as realidades não estudadas ou simplesmente ausentes destas discussões ignoradas, desconhecidas ou intencionalmente silenciadas por essa única verdade imposta na racionalidade colonial. Pensar (nos) desde Abya

\footnotetext{
${ }^{4}$ Tem muitos exemplos mas se pode lembrar casos como os barragens de Mariana em Mina Gerais ou as águas mortas em Chiloé, no sul do Chile no 2016.
} 
Yala, ${ }^{5}$ desde nossa América, e de seus aportes nos conhecimentos é um exercício necessário hoje. Olhar o que se está fazendo, o que se está produzindo, o que se está escrevendo, não pode mais que ampliar o horizonte e enriquecer estas discussões.

Os novos aportes do conhecimento no campo do desenvolvimento rural, sem pretender negar os existentes, mas problematizando, centram-se em algumas ideias eixo no cenário latino americano e só alguns casos, principalmente pelas limitações de conhecimento sobre outros lugares, mas sem desconhecer que existem em outros planos do mundo múltiplas formas que estão produzindo contribuições significativas nas lutas decoloniais e que se revelam como tema pertinente na produção de conhecimento (África, Índia e outras tantas pouco nomeadas). Retomam-se as palavras que falam que para libertar nossas sociedades de qualquer opressão precisa-se compreender e resolver os problemas criados no mesmo centro da modernidade e capitalismo, só é possível olhares mais plurais desde outra perspectiva civilizatória com bases na crítica e no desaprender dos cânones estabelecidos (Composto e Navarro, 2014).

Na década dos 90 e principalmente no início dos 2000, começam a emergir ou se fazer visíveis, no plano da academia, uma quantidade importante de reflexões onde se expõe que se pode pensar as vidas e as realidades além da ideia economicista e racional que tem dividido 0 planeta e padronizado a existência. Perspectivas, ações e tendências que fazem parte do pensamento crítico e que Escobar (2014) agrupa em cinco áreas emergentes que sem distanciar-se e com entrecruzamentos podem caracterizar este cenário: Descolonização epistêmica; alternativas ao desenvolvimento e bom viver; transição ao pós-extrativismo, crises civilizatórias e alternativas à modernidade; e a lógica comunal, relacional e pluriversos. Campos, ainda em discussão, que emergem como ideia força que de uma parte se propõem como alternativa do desenvolvimento ou como realidades sempre presentes nas comunidades andinas que fazem parte de seus modos de vida, de existir no mundo ou senti e pensar nele.

Fazemos parte de um momento onde mudar a perspectiva teórica- ontológica é fundamental para compreender, assumir e aportar na transformação do mundo, assim o suma q'amana, suma kawsay, bom viver, viver bem, são alguns dos conceitos principais que podem ajudar a pensar o mundo de maneira diferente o que pode significar também ruptura com o pensamento atual (Composto e Navarro, 2014). Palavras, conceitos que começam a designar aquilo a ser visualizado, embora seja difícil falar de alguns aspectos fundamentais de aquilo fora das próprias epistemologias do mundo indígena andino, enquanto são criações plurais que não podem olhar-se no marco da episteme cartesiana e que não se pretende essencializar ou idealizar, mas reconhecer como existentes.

Precisa- se clarificar que o mundo indígena, dos ancestros, ou afroamericano, dão conta de uma série de pluriversos que coexistem, porém que compartilham muitos pontos relacionados como aquele conexo à concepção da "terra", da "pachamama" onde o humano é só uma parte do cosmos e não o centro. Enquanto temos muitas ontologias dos mundos que inelutavelmente estão inter-relacionados, mas conservam suas diferenças como mundos, e com frequência envolvem perspectivas territoriais e comunais. (Escobar, 2014). Reconhecer esses mundos faz parte de ir além, de adentrar-nos nas filosofias da diferença, de visualizar sua contribuição ao pensamento decolonial.

Para Rivera (Apud Santos, 2015), Suma Q'amana, é um aforismo que tem muitas traduções e quer dizer viver bem o que significa ouvir antes de falar, dizer coisas que se sabem e não falar do que não se conhece, e rubricar as palavras com atos. Dávalos, por sua parte, o traduz como

\footnotetext{
${ }^{5}$ Abya Yala é o nome utilizado pelos indígenas Kunas para referir ao continente Americano, literalmente significa terra viva, terra no pleno da maturidade, a terra de sangre vital.
} 
vida em plenitude (Composto e Navarro, 2014) para Huanacuni (2010) suma qamaña (aymara) ou sumak kawsay (quechua), que na cosmovisão dos povos indígenas originários significa expõe o autor- que o primeiro é a vida em relações de equilíbrio e harmonia, "qamaña" aplica-se a quem sabe viver, assim "suma qamaña" se traduz como viver bem, a tradução mais ampla em aymara é: Suma: plenitude, sublime, excelente, magnífico, belo. Qamaña: viver, conviver, (estar sendo).

Nessa multiplicidade de possibilidades do termo e na intenção de não reduzir o que pode expressar uma diversidade de contextos, temos algumas iniciativas reconhecidas pela instituição, por exemplo, as constituições da Bolívia e Equador onde emergem algumas noções em relação à práxis políticas indígenas da existência, resistências e mobilizações, ainda menos reduzir-lhe a trama epistemológica da academia e seus regimes de verdade- saber que se questiona, nesse quadro se faz preciso retomar alguns autores como Alberto Acosta, Simón Yampará, Felix Patzi, entre outros que trabalham ou descrevem o que pode ser considerado eixos característicos.

Os autores consideram que existem muitas formas e significados de bom viver, Yampara (2007) por exemplo, expõe que ao falar de Suma Qamaña fala-se de paradigmas de vida, e este é bem estar e harmonia para tudo, se bem o conceito de desenvolvimento manifesta uma vida melhor, ou seja, que nós estejamos bem e melhor em relação a outro, onde não importa os demais, o paradigma de Suma Qamaña nunca vai ser melhor se não é com todos (plural e diverso); a chave é o sentido comunitário, onde esse todo não é antropocêntrico, é o cosmos, a pacha.

Acosta (2008) por sua parte o considera como uma alternativa possível que começa com imaginar outros mundos, para ele o bom viver emerge como uma alternativa e proposta que emerge das comunidades ancestrais dentro do mesmo sistema capitalista, proposta que questiona o desenvolvimento e se apresenta como conceito holístico que vai além da lógica economicista, que convoca assumir outros saberes e possibilidades. Para o mesmo autor é uma possibilidade para construir coletivamente um novo desenvolvimento, onde natureza deixa de ser um recurso e converte-se em um sujeito.

Conjugar a discussão e refletir sobre o indígena na ética e moral, propor um sistema econômico e político comunitário como unidade e estrutura de vida, alternativo à democracia liberal representativa ou socialismo autoritário é uma das sugestões de Patzi (2013) que, segundo ele, deve ser centro das discussões de bom viver no plano sistema/entorno, reconhecendo que as relações sociais de produção são onde se materializam a acumulação e exploração do sistema capitalista, ou que precisa de reformas estruturais. Não é só falar de diferenças culturais, ou práticas de sistemas de crenças no cosmos e a terra, é falar também de relações sociais econômicas e políticas num sistema comunitário que não é o capitalismo, e reconhecer que temos ontologias que não partilham o mundo, onde a categoria natureza não existe, as práticas de convivência, cosmologia entre outras estão presentes desde sempre nos povos antigos, incluso os da Europa, e que o racionalismo da modernidade e suas práticas depredadoras tem arrasado elas, e com suas ecologias e ontologias.

Estes autores apontam ao mesmo, o questionamento do modelo desenvolvimentista de sistema capitalista com a visualização de uma nova forma de viver no mundo, embora uma particularidade de Acosta seja que o considera uma alternativa, algo que pode ser, enquanto os outros autores é algo que está ocorrendo desde sempre nos povos indígenas e que pode converter-se em uma possibilidade para as comunidades diferentes a estas. Delgado, considera que como proposta anti- antropocêntrica Suma Qamaña, insiste no princípio feminista da Pacha, na economia comunitária onde o principal é a reciprocidade e o intercambio, a 
autonomia, a desmercantilização da natureza e a descriminalização dos movimentos sociais de resistência (Rivera, 2015).

Neste olhar não é que a economia deixe de ser um ponto de interesse, mas não é o principal o único, entra em jogo e diálogo com outros temas e muda o foco como é concebida no desenvolvimento ocidental, ou seja, deixa de ser predadora e produtivista e passa a ser solidaria, uma economia comunal onde a exploração e dominação não têm lugar, que funciona em lógicas de reciprocidade e complementaridade nos cenários locais e com sistemas políticos próprios. Ele não significa que os indígenas e camponeses do mundo andino não sejam extrativistas, mas o conhecimento deles se baseia numa cosmogonia diferente, onde o cosmos é um todo relacional de natureza e forças sobrenaturais que sustenta um conhecimento local, baseado nas práticas ancestrais que sugerem uma noção conservacionista da natureza, sempre na busca do equilíbrio. Seguindo a Escobar (2014) é uma ontologia relacional que não pode ser estudada desde a ontologia dual que nós herdamos de ocidente.

Encontra-se pertinente para fechar esta reflexão retomar as palavras de Rafael Bautista (2010), onde sugere que o viver bem se torna um horizonte de referência, onde o viver bem é 0 horizonte que o sujeito se propõe como modo qualificado de vida, não é viver por viver, mas é a responsabilidade que envolve o viver mesmo. Assim, é fazer um chamado a pensar desde outros paradigmas com desejos decolonizadores, a reinventar-nos olhando aqueles legados ancestrais que foi dissociado na ruptura abrupta feita pelo ocidente.

\section{Uma mirada desde a Amazônia boliviana}

Finalmente se podem mobilizar alguns destes conceitos problematizados aos olhos de realidades que habitam as margens do mundo colonial. De uma interpelam desde sua existência as lógicas reducionistas antes descritas e de outra entregam o senso complexo aos mundos que ficam fora do foco colonial. Para isto alude-se ao que produz o encontro com diferentes mundos indígenas da ribeira do rio Iténez (Guaporé) na Amazônia boliviana, onde o corpo pesquisador entra em interação com uma pluralidade de práticas que de diferentes formas - cantos, danças, refeições, jogos, entre outras atividades diárias - ativaram os sensos como parte de um todo complexo.

De acordo com informações coletadas durante a revisão da literatura, as chamadas terras baixas $^{6}$ e principalmente a faixa amazônica teceram uma série de histórias de tipo mítico, especulativo, em razão da desinformação e pouco conhecimento devido à sua localização na geografia e dificuldade de acesso à área. Muitos dos primeiros escritos referentes à vida nestes territórios respondem às memórias dos missionários franciscanos e jesuítas que, no século XVIII, entraram na área a partir da base missionária de Santa Cruz.

Neste mesmo século, a casca da quina ou quinina foi descoberta, gerando uma alta demanda no mercado mundial, favorecendo as primeiras migrações e colonização (Estrella, 1995), fato que teria continuidade e aumentaria durante a terceira parte do século XIX, onde a Amazônia começa a existir para o sistema institucional da Bolívia devido ao grande valor da borracha, que, da mesma forma que a atividade de mineração, foi orientada para a exportação (Roda, 1995).

Como selvagens e bárbaros ou sanguinários inimigos do progresso, são caracterizadas por expedicionárias, militares e missionárias, as populações amazônicas presentes durante suas

\footnotetext{
${ }^{6}$ Por terras baixa Isabel Muñoz Reyes refere-se ao território compreendido entre o centro e a parte noreste do estado plurinacional da Bolívia, o qual se divide em três regiones: A Amazônia ao norte, a chiquitania ao centro e o Chaco, no sur.
} 
viagens a estas terras com o propósito de explorar a casca da cinchona, goma, amêndoa e outros produtos. Vários séculos depois, é no próprio processo de encontro com estes territórios onde se traduz parte do que acontece no contato com esses mundos e que desloco essa ideia, às vezes um pouco romântica, às vezes um tanto exótica, de uma Bolívia indígena que circula por grande parte do mundo das agências de turismo e até alguns circuitos acadêmicos, onde se projeta uma Bolívia Andina de Quechuas e Aymaras - embora mais da metade de sua população se identifique como herdeira dos Incas dos Andes - parte de uma simples posição essencialista ou talvez um tanto funcional, que ignora a multiplicidade de vidas e mundos que coexistem neste território demarcado pela figura moderna do estado nação.

Se bem na atualidade, a constituição política do estado plurinacional da Bolívia incorpora o reconhecimento de nações e povos indígenas, isto pode se pensar dentro da lógica multicultural própria de várias constituições de América Latina, onde as políticas de inclusão faziam parte da configuração uninacional. Nestes, as diversidades dos povos, principalmente afrodescendentes e indígenas, possam ser inclusos na sociedade tal como está conformada, respeitando seus patrões políticos e administrativos. (Walsh, 2008). No caso da Bolivia, não pode se desconhecer que a promulgacão da constitucão do ano 2009 tem permitido que comunidades diversas comecem o caminho da reividincacão de seus direitos pelas terras e sua própria existência.

Sem aprofundar nestas discussões o que se destaca do encontro com as comunidades amazônicas, pincipalmente itonamas, tem que ver com os eixos que orientam sua relação com o território, que além de necessitar acesso a terras, demanda autonomia enquanto suas relações com as diferentes formas de vida nela presentes ficam fora das margens da razão ocidental.

A propriedade coletiva da terra é fundamental no paradigma indígena original, que nas palavras de Huanacuni (2016) compreende uma concepção cosmogônica comunitária, onde a comunidade não é entendida apenas em termos de relacionamento social, mas também de uma relação profunda com a vida. Reciprocidade, complementaridade e redistribuição se tornam princípios de vida multidimensionais com respeito, onde a individualidade não desaparece, mas emerge em sua dimensão complementaria. Um fato que pode ser observado ao passar por esses corredores amazônicos, onde embora cada um ou em comunidade trabalhe a terra em que trabalhou toda a sua vida ou que tenha sido herdado familiarmente, ele continua priorizando o comunal que está presente tanto nas celebrações rituais de chuva ou de semeadura, como na constante troca material e simbólica. Ou seja, não só de tudo que nasce dela, mas de tudo que ela exige.

Ter autonomia sobre seus territórios é um eixo central na vida ancestral, lugar desde onde o conhecimento ancestral manifesta-se de maneira diversa em extensas redes que geralmente se inserem no paradoxo de um sistema que transita entre o que poderíamos caracterizar como abandono, omissão, silêncio, transgressão multitemporal, mas também autonomia, organização, resistências, que de uma parte faz uma denúncia, mas ao mesmo tempo é força criadora. $\mathrm{E}$ essa criação pode ser observada em diferentes cenários, um deles associado às práticas - ritual ou não - de cura onde a capacidade de "agência" dos membros da comunidade comprometida com as várias funções de cura em relação aos outros é indiscutível seres dos mundos que habitam.

Nesses relacionamentos com as diferentes expressões da vida pode-se detalhar outras particularidades do mundo indígena amazônico, nas que se destaca respeito para com o mundo que habitam -humano ou não- e seus seres. Fato que dá conta da forma integrada na que os itonamas e outras comunidades próximas à ribeira do Rio Iténez, se relacionam com os elementos naturais e que caracteriza múltiples práticas e ações onde se expressa um sentido 
profundo de unidade com os mundos, destacando o ritual como forma de comunicação multitemporal que resiste a um mundo que sistematicamente os nega, anula e elimina.

É desde este lugar onde se interpelam conceitos como o desenvolvimento, e ganham vigência as mobilizações indígenas de luta pelo território. Elas deslocam do reduzido eixo empírico sob o qual se apresentam, não podem ser aprisionadas apenas sobre critérios socioeconômicos de desigualdade, pobreza ou mesmo destruição ambiental. Eles falam de uma memória ancestral e existência que excede os limites políticos administrativos sob os quais são entendidas. Elas falam da luta pela vida, não só humana, mas de rios, florestas e a diversidade de seres que a habitam. Os povos ancestrais -em sua diversidade- através de suas diferentes lutas, resistências e existências, buscam a "cura da terra", a recuperação e manutenção do equilíbrio dos mundos, e implicitamente assinalam e denunciam o surgimento de novas e perigosas dinâmicas que os ameaçam.

\section{Considerações finais}

As comunidades amazônicas da Bolívia nos levam a um lugar onde outros conceitos emergem como horizontes possíveis para pensar a vida em suas complexidades. Conceitos que não só fazem referência aos antes mencionados como bom viver, suma q'amana, suma kawsay, viver bem, mas inclui conceitos emergentes que dão conta de experiências e práxis coletivas lotadas de sensos pertinentes e correspondentes com a heterogeneidade da vida. Isto nos coloca ante um cenário que reclama reconhecimento e a sua vez demandam políticas que não só procurem a inclusão das comunidades nos sistemas produtivos ou destinem recursos ao incremento de processos técnicos pensados como dispositivos integradores do mundo rural ao circuito comercial. Uma demanda de reconhecimento da pluriversidade das vidas, que vão além dos tradicionais conceitos e práticas desenvolvimentistas.

No caso dos estudos em desenvolvimento rural, pode-se indicar que falar de ruralidades é também falar de mundos múltiplos, fazendo uso de Escobar (2014) e suas reflexões sobre os mundos que estão lutando por seus recursos, diretos e autonomia, que se podem ver como lutas ontológicas e entender-se como ontologias políticas relacionais, mundos em constante negociação e renegociação com outros mundos que criam forma de ver e fazer política, manifestas em práticas concretas.

O posicionamento desde uma perspectiva relacional favorece a emergência de vozes que não necessariamente construam um caminho unívoco, onde afetos, acontecimentos e desejos se encontram com as diversas expressões da colonialidade, a aproximação a ontologias relacionais consideradas como aquelas nas quais os mundos biofísicos, humanos e supernaturais não se consideram como entidades separadas, se não que estabelecem vínculos de continuidade entre eles. Onde não existe o "indivíduo", mas as pessoas em contínua relação com todo o mundo humano e não humano, e ao longo dos tempos (Escobar, 2014). É importante cá fazer claridade que falamos de ontologias e não culturas seguindo o exposto pelo mesmo autor, onde além da crítica ao conceito cultura em sí mesmo, o relativismo cultural reforça a asseveração das ciências naturais de dar-nos um postulado "verdadeiro" sobre o funcionamento real da natureza, onde a razão nutre o abismo entre a ciência moderna e as outras formas de conhecer reduzidas a culturas.

Como pesquisadores, portadores de um olhar externo que parece implicar uma dualidade assimétrica, tendemos a naturalizar e a ignorar as vantagens epistêmicas sobre a alteridade, em nosso papel de criadores de discursos e realidades que, embora nutridos pelo discurso e pela prática das comunidades com as quais nos relacionamos, nos tornamos um tipo de tradutores do significado do nativo, em termos de fim é o pesquisador que, "explica e interpreta, 
traduz e introduz, textualiza e contextualiza, justifica e significa esse significado" (Viveiros de Castro, 2002, p. 115). Essa vantagem epistêmica tende a nos tornar prisioneiros de categorias e conceitos dos quais nos é difícil tomar distância, de onde não é tão fácil perceber a emergência de dimensões epistêmicas locais, que, como no caso estudado, podem ser reveladoras das tramas fluidas dos processos da existência.

Considera-se importante e como desafio futuro aprofundar algumas reflexões que podem aportar nesta construção do chamado método, fazendo primeiro o esclarecimento que o método é uma prática guiada muito mais que um conjunto de técnicas, não é só uma metodologia, é filosofia, é uma forma de ser (Law, 2004), assim precisa-se práticas metodológicas sensíveis a heterogeneidade e indeterminação social, nisso a antropologia e sociologia simétrica podem entregar algumas luzes que precisam ser aprofundadas fazendo seguimento de algumas de suas principais e recentes produções com Latour, Mol, Singleton, Law, M'charek entre outros. Também se precisa desfazer os desejos de certeza na ideia de caminhos ou roteiros seguros e certos, assim como de conhecimentos verdadeiros, o método também é uma composição engajada a que acaba dando forma e nos conduze a sua vez a pensar as realidades que queremos.

Finalmente no campo do trabalho social, pode-se indicar que a profissão tem sido gestada no âmbito da ciência moderna e colonial em sua natureza vocacional, profissional e disciplinar (Aguayo, 2007), que o torna herdeiro do ideal emancipatório dos processos ocidentais, como a revolução industrial francesa, a política alemã, que embora sejam processos que não possam ser ignorados, acabam negando ou silenciando a dinâmica de nossos cenários caribenhos e latino-americanos. Dessa forma, temos sido um espelho da moderna ciência ocidental e com ela seus ideais homogêneos de "civilização", "desenvolvimento" e "progresso" (Gómez, 2015) que em repetidas circunstâncias nos levaram a silenciosos exercícios de violência ontológica e epistêmica para o que está instalado nas margens do projeto de modernidade.

Nesse contexto, os processos de pesquisa - ação em serviço social devem contribuir na reflexão crítica do mundo do social, no caso para pensar e criar ruralidades. O que é também pensar metáforas do impossível e impensável, fazer presente o ausente, trazer na discussão essas outras ontologias, dar conta de que existem processos de silenciamento das diferenças e que precisamos fugir da comodidade que reduz o debate e a pesquisa acadêmica.

\section{Referências}

Acosta, A. (2008). El Buen Vivir, una oportunidad por construir. Ecuador Debate, 84, 33-48.

Aguayo, C. (2007). Las profesiones modernas: dilemas del conocimiento y del poder, un análisis para y desde el Trabajo Social. Buenos Aires: Espacio Editorial.

Bautista, R. (2010). Hacia una constitución del sentido significativo del "Vivir Bien". Reflexiones urgentes. La Paz: Rincón Editores / Misión.

Batisto, G. (2015). El Crecimiento Económico es el Veneno de Nuestra época. Entrevista a Saskia Sassem. In Micromega. Acesso em: 03 abril 2017. Disponível em: http://ctxt.es/es/20151118/Politica/3014/crecimiento-economico-veneno-estado-liberalneoliberalismo-desigualdad-expulsiones-pobrezacapitalismo-depredador-

Econom\%C3\%ADa-Entrevistas.htm

Blaser, M. (2010). Storytelling Globalization from the Chaco and Beyond. Durham and London: Duke University Press.

Cano, W. (1999). "América Latina. Do desenvolvimentismo ao neoliberalismo". In: Fiori, J. L. (Org.). Estados e Moedas no desenvolvimento das nações. Petrópolis: Vozes.

Castro-Gómez, S., Grosfoguel, R. (2007). "Giro decolonial, teoría crítica y pensamiento heterárquico". In: Castro-Gómez, S.; Grosfoguel, R. (Org.). El giro decolonial. 
Reflexiones para una diversidad epistémica más allá del capitalismo global. Bogotá: Siglo del Hombre Editores.

Composto e Navarro (Comp). (2014). Territorios en disputa. Despojo capitalista, luchas en defensa de los bienes comunes naturales y alternativas emancipatorias para América Latina. Ciudad de México: Bajo Tierra.

Constitución Política del Estado Plurinacional de Bolivia. (2009).

Escobar, A. (2007). La invención del Tercer Mundo: construcción y deconstrucción del desarrollo. Bogotá: Norma.

Escobar, A. (2005). Más allá del Tercer Mundo. Globalización y diferencia. Bogotá: Instituto Colombiano de Antropología e Historia.

Escobar, A. (2014). Sentipensar con la tierra. Nuevas lecturas sobre desarrollo, territorio y diferencia. Medellín: Ediciones UNAULA.

Estrella, E. (1995). Plantas medicinales del Amazonas. Bolivia: Passim.

Favareto, A. (2010). As políticas de desenvolvimento territorial rural no Brasil. Perspectiva -uma década de experimentações-, 1 (2), 47-63.

Fonseca, P. (2015). Desenvolvimentismo: a construção do conceito. Instituto de Pesquisa Econômica Aplicada. Brasília-Rio de Janeiro: Ipea.

Gomez, E. (2015). La formación profesional en Trabajo Social: Avances y tensiones en el contexto de América latina y el Caribe. En: 2 Conferencia presentada en el marco del XXI Seminario Latinoamericano de Escuelas de Trabajo Social. Ciudad de México: Anais da 2 conferencia presentada en el marco del xxi seminario latinoamericano de escuelas de trabajo social "A 50 años del Movimiento de reconceptualización". Ciudad de México.

Huanacuni, F. (2010). Vivir Bien/Buen Vivir. Filosofía, políticas, estrategias y experiencias regionales. La Paz: Coordinadora Andina de Organizaciones Indígenas, CAOI.

Huanacuni, F. (2016). "Paradigma occidental y paradigma indígena originario". Alternativas descoloniales al capitalismo colonial/moderno. Buenos Aires: Ed. Signo.

Law, J. (2004). After Method: Mess in social science research. New York: Routledge.

Leite, S. (2006). Estado, padrão de desenvolvimento e agricultura: o caso brasileiro. Estudos Sociedade e Agricultura, 13 (2), 1-53.

Long, N., Ploeg, J. V. (2011). Heterogeneidade, ator e estrutura: para a reconstituição do conceito de estrutura. En: Schneider, S., Gazolla, M. (Orgs.). Os atores do desenvolvimento rural: perspectivas teóricas e práticas sociais. Porto Alegre: Ed. UFRGS

Patzi. F. (2013). Dos concepciones contrapuestas de la ley Avelino Siñani-Elizardo Pérez. Revista Ciencia y Cultura.

Rivera, C. e Aillón. V. (2015). Antologia del pensamiento crítico Boliviano contemporâneo. Buenos Aires: Clacso.

Roda, R. A. (1995). Salud, Agricultura, Medicina tradicional en la Amazonía Boliviana: un modelo de interacción Unversidad-comunidad. Bolivia: UMSA.

Santos, B. (2015). Revueltas de Indignación y otras conversas. Bolivia: Stigma.

Viveiros de Castro, E. A. (2002). Inconstância da Alma Selvagem e Outros Ensaios de Antropologia. São Paulo: Cosac \& Naify.

Walsh, C. (2008). Interculturalidad, Estado, Sociedad: Luchas decoloniales de nuestra época. Quito: Universidad Andina Simón Bolívar / Abya Yala.

Yampara, S. (2007). Derroteros de la colonialidad y la descolonización del conocimiento. En: I Ciclo de Seminarios Internacionales: Pensando el mundo desde Bolivia (pp. 115-119). La Paz: Vicepresidencia del Estado Plurinacional de Bolivia. 
